\title{
Measurement of Shrouded Radial Compressor Stability under Eccentric Conditions
}

\author{
Suyong Kim \\ Seoul National University \\ ksy1009@snu.ac.kr \\ Seoul, Republic of Korea
}

\author{
Jieun Song \\ Seoul National University \\ jehouse5@snu.ac.kr \\ Seoul, Republic of Korea
}

\author{
Tae Choon Park \\ Korea Aerospace Research Institute \\ origel@kari.re.kr \\ Daejeon, Republic of Korea
}

\author{
Kilyoung Kim \\ Hanwha Power Systems \\ kil0.kim@hanwha.com \\ Seongnam-si, Republic of Korea
}

\author{
Seung Jin Song \\ Seoul National University \\ sjsong@snu.ac.kr \\ Seoul, Republic of Korea
}

\begin{abstract}
This paper reports on the measurement of the impact of impeller eccentricity on the stability of a radial compressor. The test radial compressor is a shrouded type with a vaneless diffuser. The relative eccentricity between the impeller and the casing has been achieved by offsetting the casing with precision shims. The eccentric impeller induces tangential flow redistribution, resulting in non-axisymmetric flow field, especially at the impeller exit. At the design condition, eccentricity has little influence on the compressor pressure rise. However, near the instability onset point, pressure rise decreases slightly as the eccentricity is increased. Under the baseline conditions, the compressor goes directly into classic surge at the flow coefficient of 0.0218 . However, under eccentric conditions, the compressor goes into rotating stall first and then goes into surge. Before going into rotating stall, the compressor exhibits a modal-type stall behavior. With increasing eccentricity, rotating stall onset flow coefficient increases, but the subsequent surge appears at the same flow coefficient of 0.0218 .
\end{abstract}

\section{INTRODUCTION}

Compressors are used widely in various fields, including space, aeronautical, automotive, oil \& gas, and industrial applications. Yet, compared to axial compressors, less is known about the instability in radial compression systems even though such instabilities can degrade performance and cause mechanical damage. Furthermore, compressors often operate under eccentric conditions (Figure 1) for various reasons such as casing distortion, shaft bending, or rubbing.
Studies on the effects of eccentricity on stall margin have been done in axial compressors. Graf et al. (1997) measured and found degraded performance and decreased stall margin under eccentric condition in a 4-stage low-speed axial compressor. They also developed a parallel-compressor model to predict such eccentricity effects. Young et al. (2017) reported that the tip-clearance eccentricity only influences peak pressure rise at stall onset but not that at the design point in a low-speed axial compressor. Pointing out discrepancy between their experimental data and predictions with the Graf model assuming high solidity, they suggested a CFD model which considered radial flow redistribution to accurately predict rotating stall onset.

In a high-speed transonic compressor, Cameron et al. (2007) measured intermittent growth and decay of "spiketype" rotating stall disturbances under eccentric conditions. They found the disturbance grew as the tip clearance narrowed to its minimum and decayed as the tip clearance expanded to

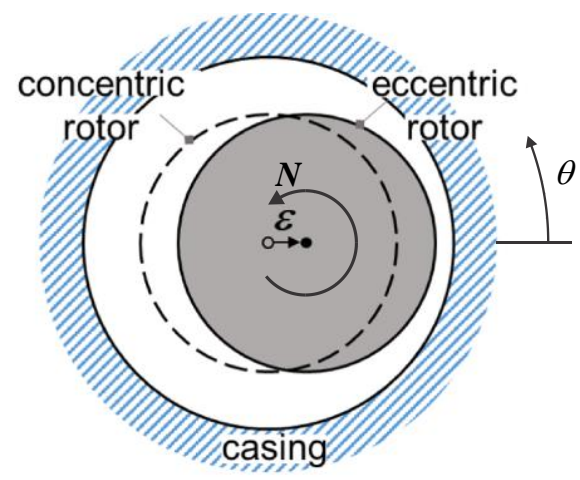

Figure 1 Schematic of Concentric/Eccentric RotorCasing Configuration. 
its maximum at the stall inception. Using the same facility as Cameron et al., Bennington et al. (2010) calculated the location in which momentums of incoming passage flow and tip-leakage flow were balanced. They argued that compressor exhibits rotating stall when this momentum balance breaks down at the rotor leading edge with the largest tip clearance. Jungst et al. (2018) measured compressor performance, stability margin, and flow redistribution due to eccentricity in a 1.5-stage transonic axial compressor. Similar to Young et al. (2017), they found that eccentricity degrades the performance and stall margin. Thus, previous research on axial compressors found that eccentricity leads to non-axisymmetric flow and increased stalling flow coefficient.

However, previous studies have all focused on axial compressors, and eccentricity effects on the stability of radial compressors have not yet been examined. Therefore, this study aims to measure the impact of eccentricity on the stability of a radial compressor. Specifically, this study aims to answer the following questions:

How does the impeller eccentricity affect

a) the flow field upstream and downstream of the compressor;

b) compressor pressure rise;

c) instability onset flow coefficient; and

d) type of compressor instability?

\section{EXPERIMENTAL SETUP}

Experiments have been performed at a radial compressor test rig in the Korea Aerospace Research Institute (KARI). The test compressor is driven by a radial turbine and has a shrouded impeller with an exit diameter of $153 \mathrm{~mm}$, a vaneless diffuser, and an axisymmetric collector as shown in Figure 2. The air in the collector discharges through two exit ducts installed with $180^{\circ}$ apart. Nominal clearance of the eyelabyrinth seals is $0.91 \mathrm{~mm}$. Greitzer's B parameter of the compressor facility is 1.83 . Other information about the compressor is listed in Table 1, and detailed experimental setup is provided by Kim (2017) and Song (2018).

For compressor operating point measurement, mass flow rate, rotating speed, ambient temperature and pressure, static pressure at the impeller inlet, diffuser inlet and exit, and total pressure at the diffuser exit have been measured (Figure 2.a).

The uncertainties (with $95 \%$ confidence interval) of the flow coefficient $(\phi)$ and pressure rise coefficient $(\psi)$ are $\pm 0.528 \%$ and $\pm 0.323 \%$ of measured values, respectively. For instability detection, a total of 32 fast-response pressure transducers (Kulite sensors) have been used. At each meridional location (impeller inlet, diffuser inlet, seal inlet, and second seal gland), eight fast-response pressure transducers have been placed around the casing in equal increments (Figure 2.b).

Impeller eccentricity has been adjusted by shifting the casing (blue part) relative to the rotor center line by using precision shims as indicated in Figure 2. Using two gap sensors installed at the exit of the eye-labyrinth seals, running eccentricity of rotor has been continuously monitored. The signals from the gap sensors and fast response pressure
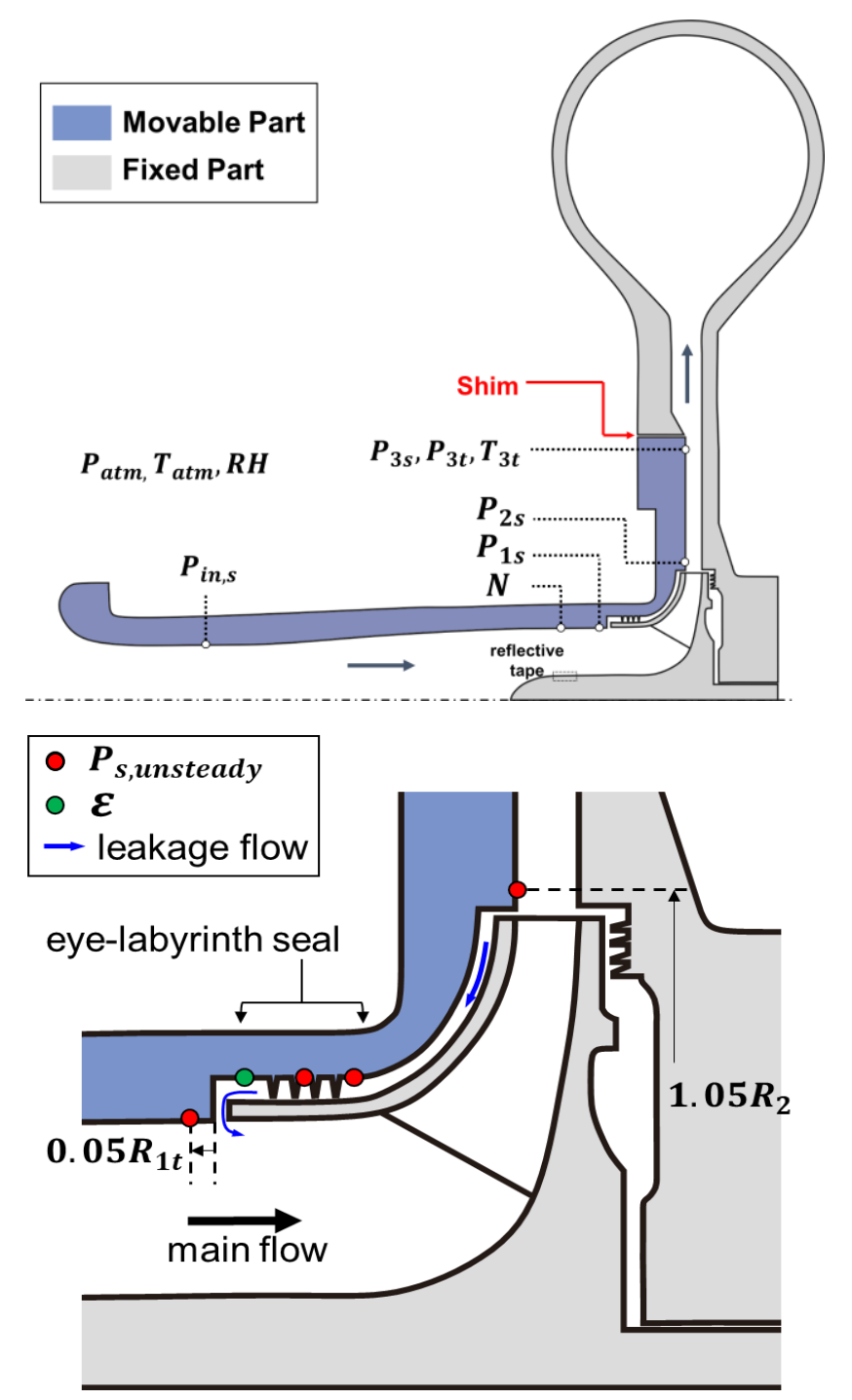

Figure 2 Schematics of Test Section and Instrumentation: (a) Steady Measurement, (b) Unsteady Measurement.

Table 1. Test Compressor Parameters.

\begin{tabular}{lll}
\hline \hline Item & & Value \\
\hline \hline Design & Rotational Speed $(N)$ & $40,000 \mathrm{rpm}$ \\
condition & Flow Coefficient $(\phi)$ & 0.0316 \\
& Pressure Rise Coefficient $\left(\psi_{t s}\right)$ & 0.535 \\
& Impeller exit tip Mach number & \\
& $\left(M_{t i p}\right)$ & 0.85 \\
& Reynolds number $(R e)$ & $6,500,000$ \\
\hline Impeller & Type & Shrouded \\
& Number of blades & 16 \\
& Exit Diameter $\left(2 R_{2}\right)$ & $153 \mathrm{~mm}$ \\
& Backsweep Angle (from radial) & $44.5 \mathrm{deg}$ \\
& Nominal Seal Clearance $(\bar{C} r)$ & $0.91 \mathrm{~mm}$ \\
\hline Diffuser & Type & Vaneless \\
& Diffuser Width $\left(b_{2}\right)$ & $9.19 \mathrm{~mm}$ \\
\hline \hline
\end{tabular}


Table 2 Tested Eccentricity (at Design Points).

\begin{tabular}{cc}
\hline \hline Case \# & Eccentricity $(\tilde{\varepsilon})$ \\
\hline \hline 1 (Baseline) & $7.8 \%$ \\
2 & $19.2 \%$ \\
3 & $25.3 \%$ \\
4 & $28.7 \%$ \\
5 & $37.8 \%$ \\
6 & $44.4 \%$ \\
7 & $58.7 \%$ \\
\hline \hline
\end{tabular}

transducers have been simultaneously sampled at $204.8 \mathrm{kHz}$, or 10 times the blade-passing frequency.

Eccentricity has been nondimensionalized by the nominal eye-labyrinth seal clearance $(\bar{C} r)$ as shown in Eq. (1). Thus, $\tilde{\varepsilon}$ of $0 \%$ means concentric condition, and $\tilde{\varepsilon}$ of $100 \%$ means contact between the casing and tip of the eye-labyrinth seal tooth. Uncertainty of the non-dimensional eccentricity ( $\tilde{\varepsilon})$ is $\pm 0.55 \%$.

$$
\tilde{\varepsilon}=\frac{\varepsilon}{\bar{C}_{r}}[\%]
$$

Experiments have been performed at 40,000 rpm for seven different eccentricity values (Table 2). The test eccentricity has varied from $7.8 \%$ to $58.7 \%$. Case 1 with the minimum eccentricity is referred to as the baseline case condition.

\section{RESULTS AND DISCUSSION}

\section{Upstream and Downstream Flow Field}

Figure 3 shows the effects of eccentricity on pressure nonuniformity at the impeller inlet and exit, and diffuser exit for the design condition. For this figure, circumferentially measured pressures of Case 1 have been subtracted from those of Case 7 to isolate the eccentricity effects. First harmonic pressure disturbances at all meridional locations-impeller inlet and exit, and diffuser exit - are visible. The highest pressure at the impeller inlet is located near the minimum clearance. This result indicates that the upstream flow approaching the compressor migrates preferentially toward

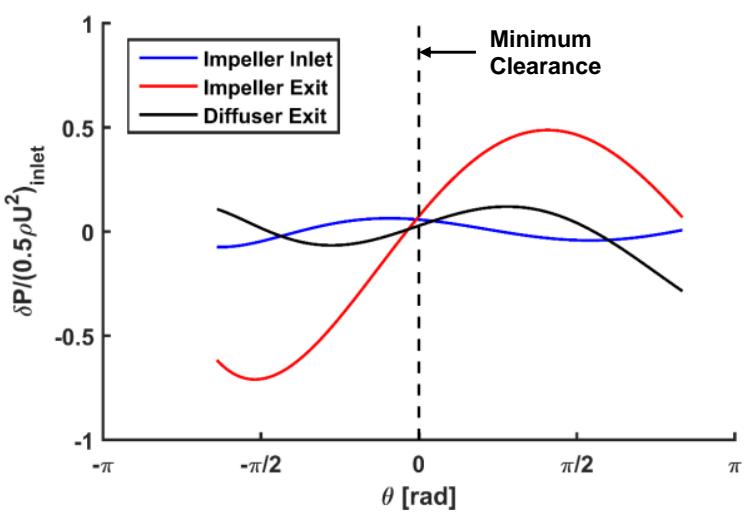

Figure 3 Effect of Eccentricity on Pressure Disturbance at Impeller Inlet and Exit, and Diffuser Exit (Design Condition $\phi \sim 0.0316$ ).

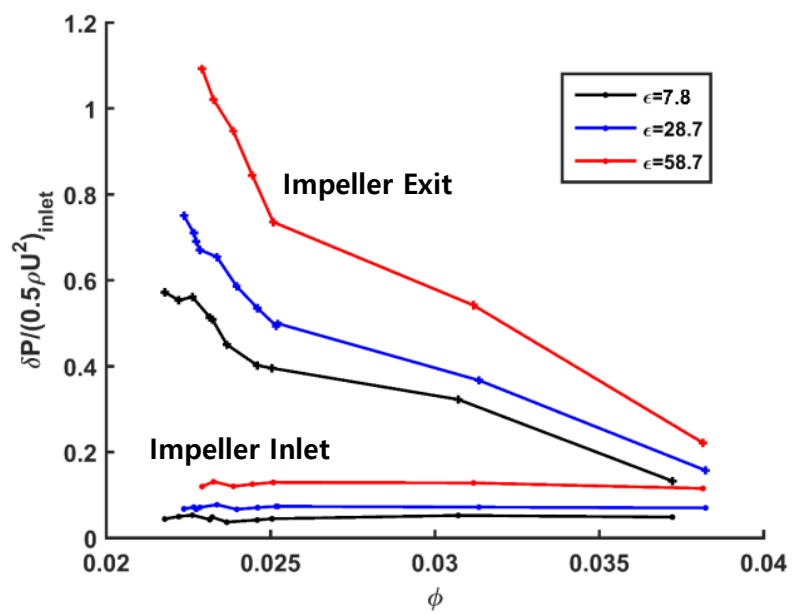

Figure 4 Effect of Eccentricity on Amplitude of Pressure Disturbance at Impeller Inlet and Exit.

the maximum gap region, resulting in higher velocity or lower static pressure near the maximum gap. Relative to that at the impeller inlet, the highest pressures at the impeller exit and diffuser exit show a phase lag of about $\pi / 2$ radians, and the largest flow non-uniformity occurs at the impeller exit. One can hypothesize that the impeller adds kinetic energy to the flow, magnifying the circumferential flow non-uniformity as the flow goes through the impeller. Farther downstream, the flow non-uniformity is likely reduced due to the decay of the eccentricity potential effects along with diffusion and mixing in the vaneless diffuser. Thus, eccentricity results in the largest pressure non-uniformity at the impeller exit. Figure 4 shows the amplitudes of nondimensional pressure disturbances for select eccentricities plotted vs. flow coefficient. Flow coefficient does not influence the pressure disturbance at the impeller inlet. In contrast, the pressure disturbance at the impeller exit increases in magnitude as the flow coefficient is decreased.

\section{Effect of Eccentricity on Compressor Characteristic}

Figure 5 shows the compressor characteristic curves of four eccentricity cases until rotating stall appear at the design

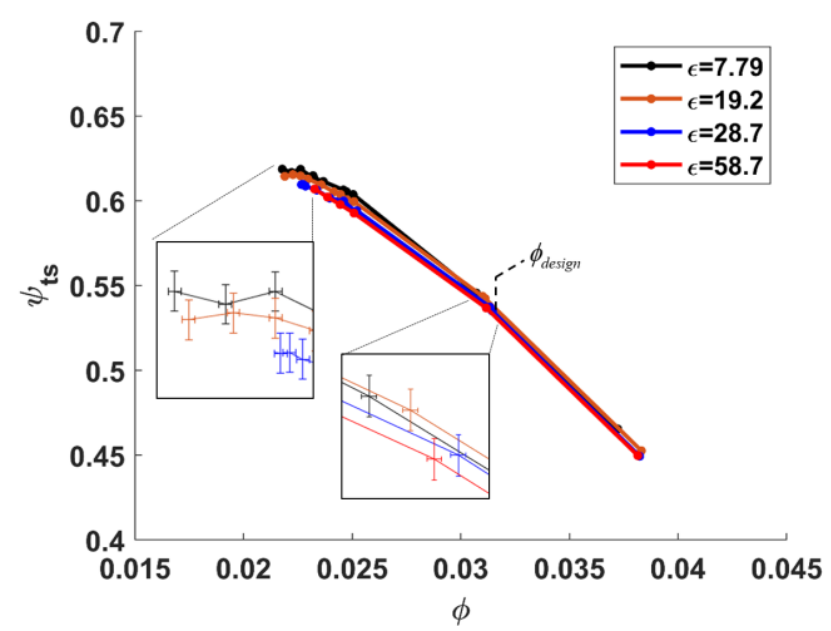

Figure 5 Compressor Characteristic at $40,000 \mathrm{rpm}$ (Total-to-Static Pressure Rise Coefficient vs. Flow Coefficient) 


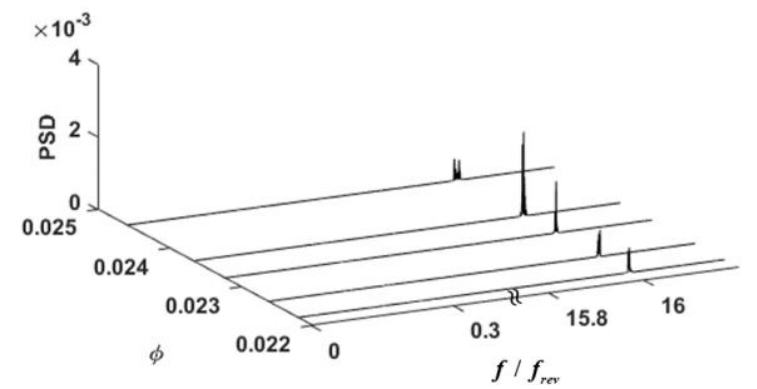

Figure 6 Power Spectral Density of Diffuser Inlet Pressure from a Single Transducer: $\tilde{\varepsilon}=7.8 \%$

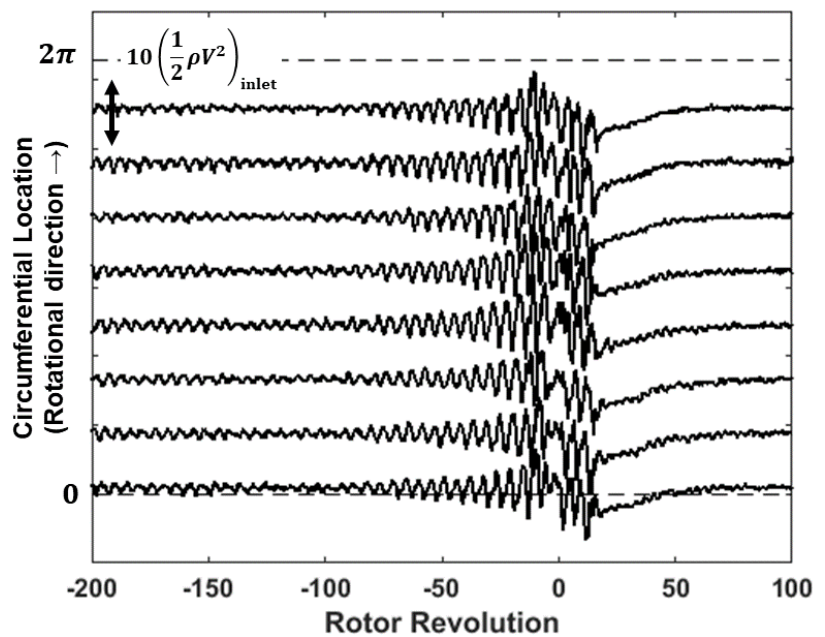

Figure 7 Diffuser Inlet Pressure Traces at Rotating Stall Inception (Case 1) at $\phi=0.0218$ (Surge at 0 Rotor Revolution)

speed of 40,000 rpm. At the design flow coefficient ( $\phi=0.0316$ ), change in pressure rise due to eccentricity is negligible, and pressure rise coefficients are almost within the uncertainty. At near stall conditions, however, the compressor pressure rise clearly decreases with increase in eccentricity.

\section{Effect of Eccentricity on Compressor Instability}

\section{Baseline compressor instability}

In this study, rotating stall and surge have been analyzed according to Tryfonidis et al. (1994). The onset of rotating stall has been defined as the flow coefficient when the dominant frequency changes from the blade passing frequency to other arbitrary frequency in the Fourier transform analysis. Then, to identify the modes of rotating stall and propagation speeds, spatial Fourier transform analysis has been used. The surge onset has been defined as the flow coefficient when the peak in the zeroth-order spatial Fourier coefficient is observed.

Figure 6 shows the power spectral density (PSD) amplitude plots for the baseline Case 1 at varying flow coefficients. Frequency has been normalized by the rotational frequency, and blade passing frequency (BPF) shows up as 16 times the rotational frequency. In the baseline condition, only the blade passing frequency is visible for flow coefficients greater than 0.0218 (Figure 6). At $\phi=0.0218$, both modaltype rotating stall and surge occur simultaneously. This process is shown in more detail in Figure 7 which shows the path-time graph of unsteady static pressure signals (from 8 aziumthal locations) plotted vs. nondimensional time at the diffuser inlet for $\phi=0.0218$. Two cells of weak modal waves rapidly develop into rotating stall of $f / f_{\text {rev }}=0.191$ from 100 to 0 rotor revolutions. Then, the compressor goes into surge at the 0th rotor revolution. Consequently, the baseline compressor exhibits the coupled mode of rotating stall and surge at the stalling flow coefficient of 0.0218 , commonly referred to as "classic surge" in the literature (Rose et al., 2003).

\section{Eccentric compressor instability}

For eccentricities greater than $25.3 \%$, peaks with magnitudes comparable to those of BPF appear for flow coefficients greater than 0.0218 at $f / f_{\text {rev }}=0.181$ (Figure 8 ) due to the development of modal waves. Thus, the eccentric compressor first goes into rotating stall at flow coefficient values greater than 0.0218 (the surge-onset flow coefficient of

(a)

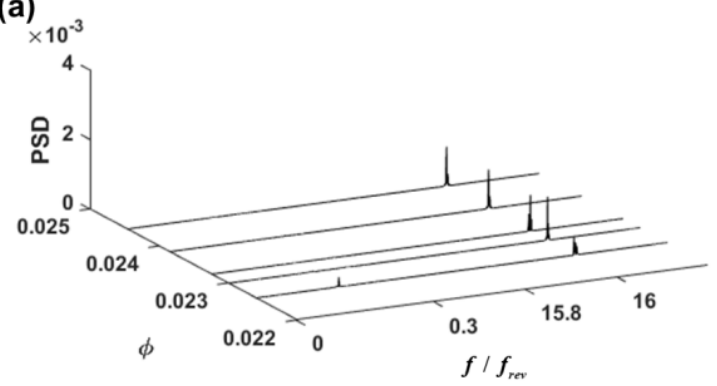

(b)

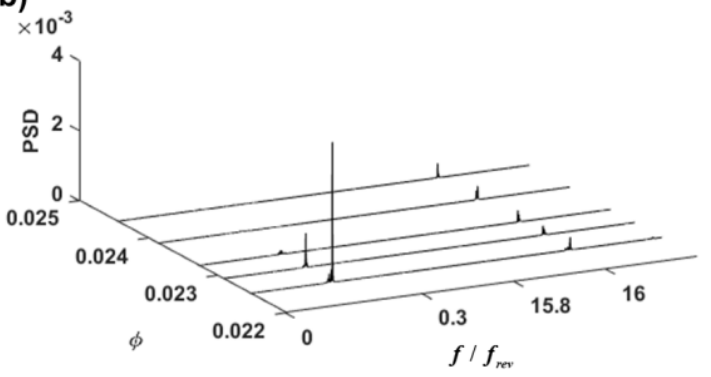

Figure 8 Power Spectral Density of Diffuser Inlet Pressure from a Single Transducer:

(a) $\tilde{\varepsilon}=25.3 \%$, (b) $\tilde{\varepsilon}=58.7 \%$

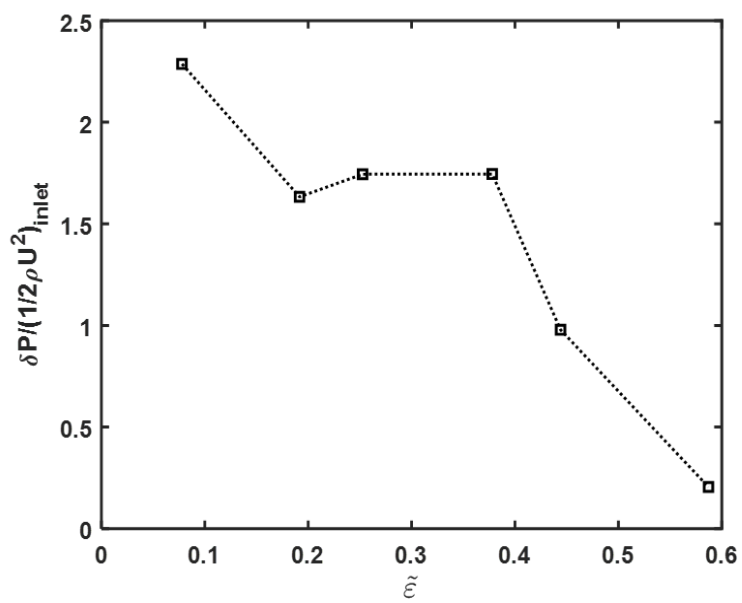

Figure 9 Effects of Eccentricity on Surge Strength 


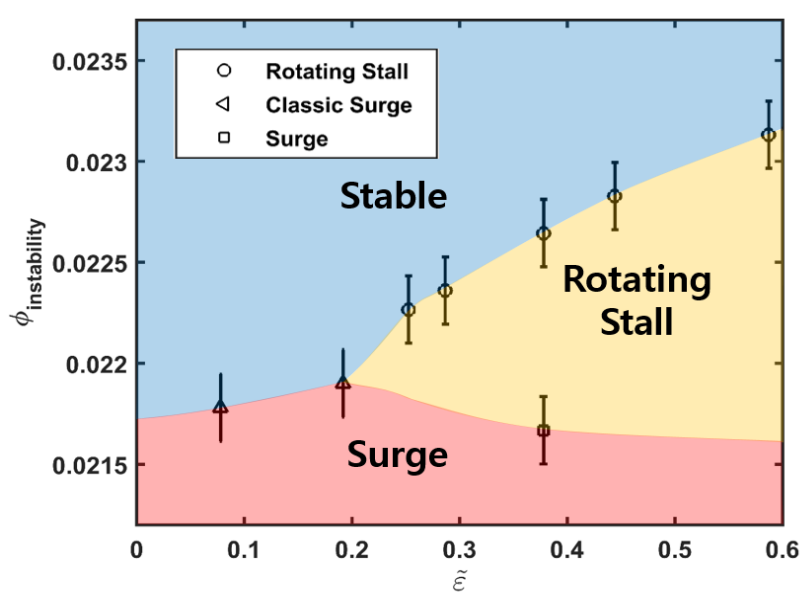

Figure 10 Effects of Eccentricity on the Onsets of Rotating Stall and Surge

the baseline compressor). With increasing eccentricity, the rotating stall onsets at increasing values of flow coefficient. Subsequently, however, the eccentric compressor goes into surge at the flow coefficient value of 0.0218 , just like the baseline compressor. Finally, it should be pointed out surge under eccentric conditions is not as intense as that under baseline conditions as shown in Figure 9.

Propagation speed and the number of stall cells are not influenced by eccentricity. The number of stall cells remains at two for all eccentricity levels. In addition, the propagation speed remains practically constant, changing from $f / f_{\text {rev }}=0.191$ for eccentricities less than $19.2 \%$ to $f / f_{\text {rev }}=0.181$ for eccentricities greater than $25.3 \%$.

Figure 10 shows the instability map which shows the instability onset flow coefficient plotted vs. eccentricity. For eccentricities less than $19.2 \%$, the compressor goes directly into classic surge at $\phi \sim 0.0218$. For eccentricities greater than $19.2 \%$, the compressor first goes into rotating stall and then goes into classic surge. The rotating stall-onset flow coefficient increases linearly with eccentricity, but the surgeonset flow coefficient remains practically constant at $\phi \sim 0.0218$.

\section{CONCLUSIONS}

The influence of impeller eccentricity on the stability of a shrouded radial compressor has been measured for impeller eccentricity ranging from $7.8 \%$ to $58.7 \%$ of the nominal labyrinth seal clearance. The following are the conclusions from this research:

Impeller eccentricity induces tangential flow redistribution, resulting in a circumferentially non-uniform pressure distribution upstream and downstream of the impeller. The amplitude of non-uniformity reaches its maximum at the impeller exit. The impeller exit pressure nonuniformity increases in magnitude with increasing eccentricity and decreasing flow coefficient. Corresponding magnitude at the impeller inlet remains independent of flow coefficient.

Pressure rise near the instability onset condition decreases as eccentricity increases, but pressure rise at design condition is not affected by eccentricity.
The baseline compressor goes directly into classic surge at the flow coefficient of 0.0218 . On the other hand, the eccentric compressor first goes into rotating stall and then goes into surge.

The rotating stall onset flow coefficient increases linearly from 0.0218 to 0.0232 as eccentricity increases from $7.8 \%$ to $58.7 \%$. In contrast, the surge onset flow coefficient is not affected by eccentricity.

\section{NOMENCLATURE}

Variables

$\begin{array}{ll}a & \text { Speed of sound } \\ A_{c} & \text { Characteristic area } \\ B & \text { Greitzer's B parameter }=\frac{U}{2 a} \sqrt{\frac{V_{p}}{A_{c} L_{c}}} \\ \bar{C}_{r} & \text { Mean labyrinth seal clearance } \\ D & \text { Diameter } \\ L_{c} & \text { Characteristic length } \\ \dot{m} & \text { Mass flow rate } \\ M & \text { Mach number }=U / a \\ N & \text { Rotational speed } \\ P & \text { Pressure } \\ r, R & \text { Radial location } \\ \operatorname{Re} & \text { Reynolds number }=\frac{\rho U D_{2}}{\mu} \\ T & \text { Temperature } \\ U & \text { Impeller exit velocity } \\ V_{p} & \text { Plenum volume } \\ x & \text { Axial location } \\ \varepsilon & \text { Center offset } \\ \tilde{\varepsilon} & \text { Eccentricity, Eqn }(1) \\ \mu & \text { Viscosity } \\ \rho & \text { Density } \\ \phi & \text { Flow coefficient }=\frac{\dot{m}}{\rho N D^{3}} \\ \psi & \text { Pressure rise coefficient }=\frac{P_{3}-P_{1}}{\rho U^{2}} \\ & \end{array}$

$\begin{array}{ll}\text { Subscripts } & \\ 1 & \text { Impeller inlet } \\ 2 & \text { Diffuser inlet } \\ 3 & \text { Diffuser exit } \\ \text { ts } & \text { Total-to-static } \\ \text { t } & \text { Tip } \\ \text { h } & \text { Hub }\end{array}$

\section{ACKNOWLEDGMENTS}

This work was financially supported by Hanwha Power Systems, the Korean Aerospace Research Institute, the BK21 
Program of the Korean Government; and the Institute of Advanced Machines and Design of Seoul National University.

\section{REFERENCES}

Bennington M. A., Ross M. H., Cameron J. D., Morris S. C., Du J., Lin F., and Chen J. (2010). An Experimental and Computational Investigation of Tip Clearance Flow and Its Impact on Stall Inception. Proceedings of ASME Turbo Expo, GT2010-23516. doi:10.1115/GT2010-23516.

Cameron J. D., Bennington M. A., Ross M. H., Morris S. C., and Corke T. C. (2007). Effects of Steady Tip Clearance Asymmetry and Rotor Whirl on Stall Inception in an Axial Compressor. Proceedings of ASME Turbo Expo, GT200728278. doi:10.1115/GT2007-28278.

Graf M. B., Wong T. S., Greitzer E. M., Marble F. E., Tan C. S., Shin H.-W., and Wisler D. C. (1998). Effects of Nonaxisymmetric Tip Clearance on Axial Compressor Performance and Stability. ASME Journal of Turbomachinery 120 (4), 648-661. doi:10.1115/1.2841774.

Jungst M., Liedtke S. Schiffer H. P., and Becker B. (2018). Aerodynamic Effects in a Transonic Compressor with Nonaxisymmetric Tip Clearance. Proceedings of ASME Turbo Expo 2018, GT2018-75404. doi:10.1115/GT201875404.

Kim S. (2017). Measurement of Eccentricity Effects on Stability of a High-Speed Shrouded Centrifugal Compressor. M.S. Thesis, Seoul National University.

Rose M. G., Irmler K., Schleer M., Stahlecker D., and Abhari R. S. (2003). Classic Surge in a Centrifugal Compressor. Proceedings of ASME Turbo Expo, GT200338476. doi:10.1115/GT2003-38476.

Song J. (2018). Non-Axisymmetric Flow in a Shrouded Radial Compressor. Ph. D. Thesis, Seoul National University.

Tryfonidis M., Etchevers O., Paduano J. D., Epstein A. H., and Hendricks G. J. (1994). Pre-Stall Behavior of Several High-Speed Compressors. Proceedings of ASME Turbo Expo, 94-GT-387. doi:10.1115/94-GT-387.

Young A. M., Cao T., Day I. J., and Longley J. P. (2017). Accounting for Eccentricity in Compressor Performance Predictions. ASME Journal of Turbomachinery 139 (9), 901008-1-10. doi: 10.1115/1.4036201.

\section{APPENDIX A - ECCENTRICITY ADJUSTMENT}

Eccentricity can be adjusted by moving either the impeller (rotating part) or casing (stationary part). In this study, the latter was moved.

Figure 11 is the eccentricity adjustment part which is the interface of the blue and grey parts in Figure 2. a. The faces of the outer guide and the casing were machined as flat plate to place precision shims between them, and these adjustment parts have been orthogonally installed for two-axis adjustment.

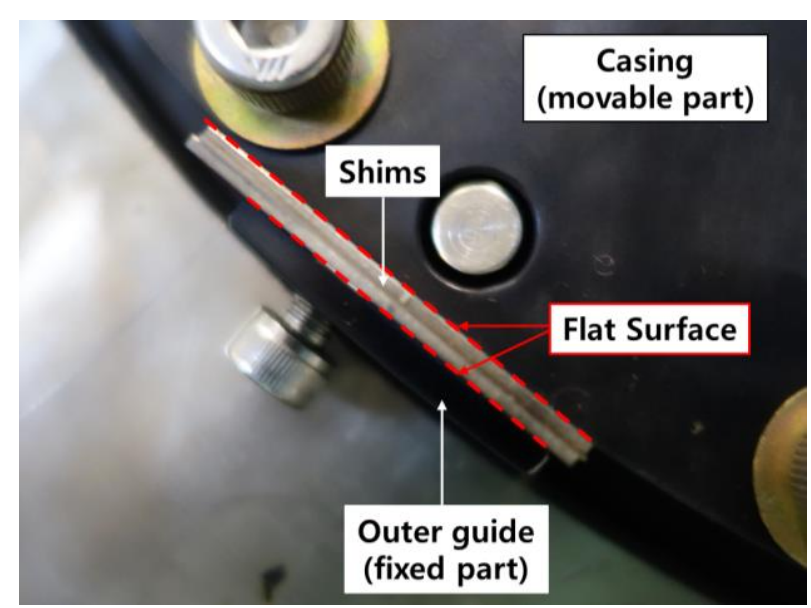

Figure 11 Eccentricity Adjustment with Precision Shims 